\title{
Metodologia projetual para educomunicar 0 desenvolvimento de coleções de moda
}

Taís Steffenello Ghisleni

Doutora em Comunicação pela Universidade Federal de Santa Maria (UFSM); coordenadora do Laboratório de Pesquisa em Comunicaşão (LAPEC) e professora do curso de Publicidade e Propaganda e do Mestrado em Ensino de Humanidades e Linguagens do Centro Universitário Franciscano.

E-mail: taisghisleni@yahoo.com.br

Rubiana de Quadros Sandri

Professora Especialista no curso de Design de Moda e Mestranda do curso de Mestrado em Ensino de Humanidades e Linguagens da Universidade Franciscana (UFN).

E-mail: ruby_moda@yahoo.com.br

Elsbeth Léia Spode Becker

Professora Doutora. no curso de Geografia e no Mestrado em Ensino de Humanidades e Linguagens da UFN.

E-mail: elsbeth.geo@gmail.com

Resumo: Neste artigo objetiva-se descrever uma proposta de prática educomunicativa para a recriação de metodologias projetuais no ensino e no desenvolvimento de coleções de moda. A metodologia é exploratória, fundamentada na revisão bibliográfica. No texto, expõe-se uma breve compreensão sobre metodologias projetuais no desenvolvimento de coleções de moda a partir de Montemezzo (2003), Jones (2005), Barcaro (2008), Sorger e Udale (2009), Renfrew e Renfrew (2010) e Treptow (2013). Além disso, descrevem-se algumas metodologias utilizadas no design de moda e apresenta-se uma proposta de prática educomunicativa no ensino e no desenvolvimento de coleções de moda. Inferiu-se que as metodologias
Abstract: This article aims to describe a proposal for educommunicative practice to recreate design methodologies in teaching and developing fashion collections. The methodology is an exploratory research, based on a literature review. The text presents a brief understanding of design methodologies in the development of fashion collections based on the Montemezzo (2003), Jones (2005), Barcaro (2008), Sorger and Udale (2009), Renfrew and Renfrew (2010) and Treptow (2013), and describes some methodologies used in fashion design and presents a proposal for educommunicative practice in teaching and developing fashion collections. It was inferred that the design methodologies for 
projectuais para o desenvolvimento de coleções de moda podem utilizar-se de práticas educomunicativas e assim facilitarem o processo de ensino no desenvolvimento de coleções, articulando o processo colaborativo entre os alunos.

Palavras-chave: vestuário; educomunicação; ensino; design de moda; processo colaborativo. the development of fashion collections could use educational practices and thus facilitate the teaching process in the development of collections, thus articulating the collaborative process between students.

Keywords: clothing; educommunication; teaching; fashion design; collaborative process.

\section{INTRODUÇÃO}

As grandes transformações engendradas nos séculos XII e XIII geraram uma dinâmica social sem precedentes no mundo medieval e a gradual mudança no tradicional sistema feudal trouxe notáveis inovações, entre elas o renascimento urbano no mundo ocidental. A vida na cidade ofereceu uma maior referência à vida material e ao consumo e despertou a curiosidade pelo novo. Também foi nesse período que começou a surgir o indício de um hodierno sistema econômico que, mais adiante, passou a dominar as sociedades contemporâneas. O capitalismo e sua representante máxima, a classe burguesa, evidenciaram uma nova concepção de mundo e a vida material se tornou, pela primeira vez, tão importante quanto a vida espiritual.

Todas essas mudanças foram acompanhadas por novas formas de mentalidade, de cultura, da evidência da individualidade e do nascimento da consciência de si. O surgimento da ideia de indivíduo se promoveu, acima de tudo, no encontro do homem consigo mesmo, como protagonista de seu tempo e de seu meio, influenciado por eventos externos, mas capaz de agir por seus próprios impulsos. O indivíduo, nas artes, aparecerá no retratismo renascentista, que promoveu a identidade pessoal a tema absoluto, a ser buscado de todas as formas, especialmente, na aparência do indivíduo.

A mudança de percepção foi extremamente profunda e se constituiu na semente da revolução filosófica conduzida pelo humanismo. O homem se tornou o centro de todo o pensamento, a referência para o conhecimento racional e cartesiano e o principal destaque é dado à vida terrena e não mais à espiritualidade e à religiosidade. Nesse contexto de pensamento, a aparência visual e a maneira como esse novo homem se apresenta ao mundo e à sociedade ganhou grande importância.

1 BRAUNSTEIN, Philippe. A emergência do indivíduo: abordagens da intimidade nos séculos XIV-XV. In: DUBY, Georges. (org.). História da vida privada 2 : da Europa feudal à Renascença. São Paulo: Companhia das Letras, 1990.
Suntuoso ou cômodo, o traje está estreitamente ligado ao íntimo: convencemo-nos disso pelo lugar que ocupa nos diários de despesa, assim como pelas imagens de si que suscita no fim da Idade Média. O traje é sempre mais que o tecido e o ornamento, estende-se ao comportamento, determina este último, determina este último tanto quanto o põe em evidência: marca as etapas da vida, contribui para a construção da personalidade, apura a distância entre os $\operatorname{sexos}^{1}$. 
Portanto, a moda emergiu com a nova classe social, a burguesia, com a possibilidade de liberdade e democracia no que diz respeito ao indivíduo. Em meio ao cenário de transformação econômica, política, cultural e religiosa, o mundo ocidental europeu passava a ser inundado de novidades, repleto de pequenas e grandes vogas e seguramente a aparência ganhou destaque e estimulou a cópia dos trajes aristocráticos pela burguesia cada vez mais enriquecida. Cabe lembrar a criação das Leis Suntuárias, pelo édipos reais, proibindo ou limitando o uso de determinados produtos e materiais pelos diversos estratos sociais. Segundo Hunt $^{2}$, as leis proibitivas relacionadas ao vestir possuíam três motivações principais: reforçar hierarquias, privilégios e posições sociais; efeito moralizador relacionado ao luxo de acordo com diferentes camadas sociais; e protecionismo econômico, relacionado ao uso de tecidos, pedras preciosas e materiais diversos.

A dialética da cópia existente entre o que era eleito pela corte como a novidade, seguida por sua imitação pela aristocracia e depois pela elite burguesa, e finalmente sua popularização entre as classes urbanas servia de estímulo para que a corte se enfadasse e, em seguida, se dedicasse a alguma outra novidade ${ }^{3}$. Mas considerar a "cópia entre classes" como a única responsável do surgimento da moda, talvez seja demasiado reducionista, e há necessidade de considerar também outros fatores.

A existência de diferentes tipos de corporações de ofício que requeriam um vestuário específico que as identificavam e, ainda dentro destes grupos, seus membros se subdividiam em hierarquias. As distinções entre as corporações e seus grupos deveriam ser visíveis e o melhor recurso para isso era a indumentária. Em decorrência, havia uma proliferação de uniformes, insígnias e distintivos que decoravam os vestuários urbanos, aumentando ainda mais a possibilidade de composição da imagem corporal. Ademais, é necessário considerar que existiam os vários maneirismos locais e as particularidades do traje de cada região da Europa ${ }^{4}$.

Além de tudo isso, acrescenta-se o processo de desenvolvimento do "Eu", da consciência individual daqueles sujeitos históricos que, agentes de seu tempo, sofriam as consequências das profundas transformações econômicas, políticas, culturais e religiosas da época. Portanto, a construção de uma identidade e da aparência desse novo sujeito, único, passava por todos esses aspectos e a indumentária era uma das possibilidades de fazer-se representado em seus aspectos individuais.

Este contexto revela que a moda ganha um novo status quo a partir da Idade Moderna, impulsionado no desenvolvimento da imprensa e no aumento do interesse por veículos que tratavam a moda como possibilidade de criação e exteriorização do "bom gosto". O bom gosto passa a ser a primeira virtude social que, no âmbito da vida mundana, refere-se tanto à interioridade quanto à aparência dos indivíduos. [...] O gosto refere-se ao que os indivíduos são, ao que sentem em sua relação com as coisas ${ }^{5}$.

A moda como o sistema que conhecemos hoje encontrou terreno frutífero na sociedade moderna que trouxe consigo a possibilidade de transição e comunicação entre as camadas sociais, substituindo a fixidez das estruturas que eram, em grande parte, identificadas através das roupas e oficializadas pelas leis suntuárias. A posse do dinheiro, especialmente pela burguesia, tornou acessíveis os símbolos da vida
2 HUNT, Alan. Governance of the consuming passions: a history of sumptuary law. New York: St. Martin's Press, 1996.

3SHULMAN, Rachel. Sumptuary legislation and the fabric construction of national identity in early modern England. Constructing the Past, Chicago, v. 8, n. 1, 2007.

4 BRAUSTEIN, 1990

5 FLANDRIN, Jean-Louis A distinção pelo gosto. In: CHARTIER, Roger (org.) História da vida Privada 3: da Renascença ao século das Luzes. São Paulo: Companhia das Letras, 2009. p. 234-289. 


\section{comunicação \& educação • Ano XXVI • número 1 • jan/jun 2021}

6 HALL, Stuart. A identidade cultural na pós-modernidade. Tradução de Tomas Tadeu da Silva e Guaracira Lopes Louro. 11. ed. Rio de Janeiro: DP\&A, 2006

7 ALVES, Gláucia da Rosa do Amaral; BECKER, Elsbeth Léia Spode. Manuais de etiqueta e civilidade e sua influência na condução social feminina no Brasil (1940-1960). Revista Latino-americana de Geografia e Gênero, Ponta Grossa, v. 10, n. 2, p. 42-65, 2019.

8 "Complexus significa o que foi tecido junto; de fato, há complexidade quando elementos diferentes são inseparáveis constitutivos do todo (como o econômico, o político, o sociológico, o psicológico, o afetivo, o mitológico), e há um tecido interdependente, interativo e inter-retroativo entre o objeto de conhecimento e seu contexto, as partes e o todo, o todo e as partes, as partes entre si". MORIN, Edgar. Os sete saberes necessários à educação do futuro. São Paulo: Cortez, 2000, p. 38. ociosa e, no amplo e variado espaço urbano, a transformação do pensamento e das mentalidades fez surgir o indivíduo moderno como valor social. Emerge a razão, o indivíduo, a consciência, o inconsciente e o consumo, fortalecido pela Revolução Industrial alinhavada com a expansão da democracia burguesa.

A sociedade contemporânea, globalizada, acentua ainda mais os aspectos da identidade e da individualidade do sujeito. Para Hall ${ }^{6}$, a constituição da identidade acontece na relação com as pessoas que mediam os valores, sentidos e símbolos, ou seja, a cultura, para o sujeito. A identidade é, portanto, formada na interação do sujeito com a sociedade, num diálogo contínuo com o mundo. Nessa relação o sujeito se projeta e internaliza imagens e símbolos que irão constituir sua identidade numa relação dinâmica e constante.

A possibilidade de vir a ser conforme o próprio desejo está no seio da moda tal qual a conhecemos hoje. Dessa forma, a moda representa a identidade, ou, mais do que isso, a possibilidade de construção da própria identidade por parte do sujeito.

A moda é escolha pessoal e pode se revelar identitária de uma individualidade, mas, também, pode compor um fenômeno social e, neste caso, estar presente nos modos de agir, viver e sentir coletivos, e a forma mais visível de manifestação desse fenômeno é a maneira de se vestir, ou seja, o vestuário. A influência da moda no vestuário pode ocorrer como um mecanismo que regula as escolhas e as preferências das pessoas em deferência a uma espécie de "pressão social", que indica aquilo que devem consumir, usar, utilizar ou fazer. E, sob este aspecto, da moda no vestuário, o setor foi rapidamente incorporado à lógica do sistema capitalista como sendo a indústria da moda, que dita tendências e modismos.

A indústria da moda e, mais especificamente, a indústria do vestuário tem se desenvolvido rapidamente também no Brasil, e constituiu-se em um dos setores que mais move a economia, gera renda e trabalho. Essa indústria, assim como outros setores, passou por grandes transformações acarreadas da evolução tecnológica e da pesquisa de novas matérias-primas e, mais recentemente, incorporou-se às novas tendências voltadas à sustentabilidade e ao consumo consciente.

Cabe recordar que a moda, por muito tempo, foi conduzida pela substituição e pelo descarte sugeridos ou impostos pelas novas tendências que tornavam a coleção anterior superada e até "fora de moda". Assim, o setor da moda, por muitas décadas, estava associado ao "bom gosto", e as pessoas que preferiam ou não podiam seguir esses códigos acabavam por ficar, de alguma forma, afastadas da sociedade ou eram alvo de críticas de "mau gosto". O fato de se adotar ou não uma moda ou um estilo não era um ato voluntário, mas um ato regrado pelas boas maneiras da civilidade, ditado pelos manuais de etiqueta e civilidade que eram consultados pelos integrantes da elite que neles se espelhavam para desempenhar papéis e regras sociais que normatizavam comportamentos ${ }^{7}$.

Ainda no século XX, mas já na esteira das transformações do período técnico-científico-informacional e dos referenciais ecológicos, a exemplo da Carta da Terra, a civilização contemporânea, movida pelos desígnios do novo milênio e desafiada pelo pensamento complexo ${ }^{8}$, se reconhece como relação, como abertura, comunicação e solidariedade para consigo, com o outro e com as coisas do planeta. 
O supérfluo e o individualismo são incitados ao ecumênico, ao comunitário e ao reconhecimento da multiplicidade de culturas e realidade da sociedade humana.

Nesse contexto, o ser humano compreende-se cercado de possibilidades circunstanciais, de pluralismo e de uma necessária nova postura diante da vida, em todas as suas manifestações no planeta Terra. No setor do vestuário, na moda atual, acontece uma ruptura da essência da moda. Segundo Svendsen ${ }^{9}$, a lógica de substituição foi trocada pela lógica de suplementação, em que todas as tendências são recicláveis. Para tanto, os designers precisam estar preparados para esse novo mercado e, verdadeiramente, serem capazes de lançar estilos consoantes com a natureza e a preservação da vida na Terra. A moda tende a ser associada àquilo que está relacionado ao contexto de cada época, e o atual momento é desafiador, tanto nas tendências do uso de novos materiais como na consciência da preservação dos recursos naturais ${ }^{10}$. Portanto, a indústria, o mercado consumidor e principalmente o ensino para designers precisam ser verdadeiramente preparados para acompanhar o novo paradigma da humanidade: a sustentabilidade.

A moda está fortemente associada às questões voltadas ao vestuário, e a maioria dos cursos superiores mantém em comum o ensino de metodologias para o desenvolvimento do vestuário. $\mathrm{O}$ mercado de moda tem evidenciado crescimento quando se trata do contexto dos negócios contemporâneos no Brasil e no mundo. Atualmente, o Brasil é o país que tem o maior número de cursos voltados para a área de Moda. Segundo Cietta, houve uma atenção crescente voltada para as funções dos designers de profissionais na área da moda, e o resultado desse fenômeno é aumento dos cursos de moda disponíveis no Brasil. O autor apresenta um levantamento realizado na plataforma e-MEC e contabilizou 179 cursos, sendo 126 tecnológicos e 53 de bacharelado ${ }^{11}$.

A moda é cíclica e, conforme Carvalhal ${ }^{12}$, parte da premissa que quem move o mundo são as pessoas. Portanto, "se formos capazes de educá-las, instruí-las, transformá-las ou ao menos ampliar sua consciência, a solução um dia chegará”.

A moda se expressa por meio do vestuário, que é criado e desenvolvido durante um processo projetual. O designer de moda, ao projetar uma coleção de moda, concilia a inovação de materiais e a tecnologia com a interpretação cultural e, além disso, integra aspectos sociais, econômicos, estéticos e sustentáveis. Atualmente, sabe-se que não basta criar produtos com soluções estéticas apenas, pois é preciso considerar outras questões. Dentre elas, vale enfatizar que o sistema de moda precisa mudar. De acordo com Carvalhal ${ }^{13}$, ele está "se destruindo". Com isso, o autor não se refere somente ao meio ambiente, mas também ao "quanto a moda tem matado o desejo pela moda, acelerando demais, banalizando suas coleções e seus produtos", na sua maioria sem relevância ou propósito.

Vive-se um período de transformações da sociedade moderna para a pós-moderna, e, nesse contexto, Bauman ${ }^{14}$ endossa que a solidez do mundo deu lugar à fluidez, que, por sua vez, não se restringe à forma fixa, mas está em constante mudança, definida pelo autor como modernidade líquida. Esse fenômeno é marcado pela inconstância e mobilidade e direciona para a diversidade de possibilidades individuais para as atuações sociais.
9 SVENDSEN, Lars. Moda uma filosofia. Rio de Janeiro:Zahar, 2010.

$10 \mathrm{lbidem}$.

11 CIETTA, Enrico. A economia da moda: porque hoje um bom modelo de negócios vale mais do que uma boa coleção. São Paulo: Estação das Letras e Cores, 2017. p. 44.

12 CARVALHAL, André. Moda com propósito. São Paulo: Paralela, 2016. p. 55.

13 lbidem, p. 54.

14BAUMAN, Zygmunt. Modernidade líquida. Rio de Janeiro:Zahar, 2001. 


\section{comunicação \& educação • Ano XXVI • número 1 • jan/jun 2021}

Visto por esse viés, pode-se perceber que a complexidade da profissão está em perceber o contexto histórico e traduzi-lo, além de dispensar atenção às diversidades, analisar o mercado e o comportamento do consumidor, seus anseios e desejos e integrar componentes estéticos, econômicos e competitivos e, posteriormente, concretizar o projeto. Muitas vezes, nota-se que os alunos partem para a criação, deixando de lado o que dará suporte e embasamento para a coleção, ou seja, sem seguir uma metodologia, que não deve ser engessada, ou seja, deve ser flexível conforme a necessidade e o contexto. Percebe-se, portanto, a necessidade de revisão permanente e atualizada das mudanças sociais, das novas metodologias, técnicas e ferramentas que surgem para lidar com as manifestações transitórias referentes à moda ${ }^{15}$.

A educação, a sociedade e a moda vêm passando por mudanças profundas em decorrência dos avanços tecnológicos. O ensino tradicional, por sua vez, deve acompanhar as possibilidades decorrentes de tais mudanças. Para tanto, com a finalidade de integrar as práticas educativas e os processos comunicativos em espaços educativos e possibilitar a construção e reconstrução do conhecimento de maneira coletiva, por meio de uma reflexão compartilhada, a educomunicação pode significar uma excelente alternativa. Aparicci ${ }^{16}$ afirma que a

[...] educomunicação inclui, sem reduzir-se, o conhecimento das múltiplas linguagens e meios através dos quais se realiza a comunicação pessoal, grupal e social. Abrange também a formação do senso crítico, inteligente, diante dos processos comunicativos e de suas mensagens, para descobrir os valores culturais próprios e a verdade.

Entretanto, nota-se que metodologias projetuais precisam inovar e se aliar às tecnologias no sentido de introduzir novas formas no ensino, uma maneira de estimular a utilização de uma metodologia de projeto. A educomunicação pode ser eficaz, pois oferece opções de jogos, vídeos, podcast, gifs, entre outros, e se caracteriza por ser uma forma de comunicação que busca reduzir as desigualdades e promover respeito às diferenças. Essas características fazem parte, também, do novo jeito de "fazer moda". A moda, desde o seu surgimento até os dias atuais, passou por grandes mudanças, talvez a maior delas tenha sido o conceito que fez com que ela surgisse, ou seja, a mudança pela mudança.

Cabe a ponderação de Carvalhal ${ }^{17}$, que refere que é preciso resgatar a consciência e os valores humanos por meio dos aspectos reflexivos e expressivos que a moda propõe. Além e apesar disso, é necessário considerar que um produto de moda é dinâmico e, para que ele atenda à demanda competitiva de mercado e ao conceito de sustentabilidade, o designer deve escolher a melhor metodologia projetual e recriá-la para cada contexto. Nesse sentido, cabe a seguinte pergunta-problema: a educomunicação pode contribuir para o processo de recriação de metodologias projetuais no ensino e no desenvolvimento de coleções de moda?

Com base na questão exposta, tem-se como objetivo, neste artigo, discutir uma proposta de práticas educomunicativas para a recriação de metodologias projetuais no ensino e no desenvolvimento de coleções de moda. Para tanto, será necessário apresentar metodologias propostas por diferentes autores, 
enfatizando a importância de projetar um produto de moda; abordar como a educomunicação pode contribuir para o ensino; propor práticas educomunicativas aplicadas à metodologia de projeto de coleção de moda.

Assim como a sociedade, a moda está em constante evolução, e o ensino de moda precisa acompanhar esse desenvolvimento e se adequar à nova realidade e, nesse contexto, de acordo com Soares ${ }^{18}$, "o grande desafio é assumir uma inovação necessária. O campo da educomunicação é um espaço de decisões por mudanças direcionadas à integração dos talentos, tendo como foco principal o educando e seu universo de expectativas e perspectivas".

\section{METODOLOGIAS PROJETUAIS NO ENSINO E NO DESENVOLVIMENTO DE COLEÇÕES DE MODA}

Projetar uma coleção de moda em um cenário complexo, em que os valores imateriais se tornam cada vez mais relevantes é, também, uma tarefa complexa. Nessa direção, Moraes ${ }^{19}$ corrobora ao escrever que, sobre a dificuldade de decodificar um cenário complexo, entretanto, a natureza transversal e dinâmica do design pode facilitar essa decodificação da realidade, auxiliando nas diretrizes que guiem as intervenções neste contexto híbrido.

Projetar significa antever o futuro, planejar algo que ainda não se conhece. No decorrer da execução do projeto, as decisões se conectam umas às outras, inserindo novas informações e se modificando até verificar sua viabilidade, processo que acontece de forma cíclica e interativa, ou seja, o percurso projetual não deve ser entendido como um esquema fechado e linear. Nesse sentido, nota-se que autores que desenvolvem as metodologias do design discorrem sobre a importância da maleabilidade dos métodos ${ }^{20}$.

No contexto da indústria, o planejamento e desenvolvimento de produtos de vestuário de moda se desdobram de maneira complexa e acelerada. Montemezzo ${ }^{21}$, Jones $^{22}$, Barcaro ${ }^{23}$, Sorger e Udale ${ }^{24}$, Renfrew e Renfrew ${ }^{25}$ e Treptow $^{26}$ são unânimes ao destacarem o planejamento como etapa imprescindível para dar conta do cenário acelerado.

Montemezzo $^{27}$ destaca a metodologia projetual em cinco etapas. A preparação é a primeira, na qual é realizada a coleta de dados de comportamento, definido o problema, feita a pesquisa de tendências, materiais e tecnologia, além da definição do conceito gerador, ou seja, da linguagem visual. A etapa seguinte é a geração, fase em que são realizados os esboços, os estudos de modelos e as configurações. Em seguida vem a avaliação de acordo com as especificações do projeto. A etapa posterior é a concretização, o desenvolvimento tridimensional para experimentação, custo e correção adequações. A última é a etapa da documentação para a produção, a realização da ficha técnica definitiva e confecção da peça piloto ${ }^{28}$.

Jones $^{29}$ apresenta três grandes etapas: o briefing, em que se apresentam as metas e os objetivos, em seguida a fase da inspiração, a fase da apresentação e, por fim, a avaliação. Cada uma delas tem especificações como se observa na Figura 1.
18 SOARES, Ismar. Comunicação/educação, a emergência de um novo campo e o perfil de seus profis sionais. Revista Contato Brasília, v. 1, n. 1, 1999. p. 194.

19 MORAES, Dijon de. Metaprojeto: o design do design. São Paulo: Blucher 2010 .

20 SANCHES, Maria Celeste de Fátima, op. cit., 2017.

21 MONTEMEZZO, Maria C. F. S. Diretrizes metodológicas para o projeto de produtos de moda no âmbito acadêmico. 2003 $98 \mathrm{f}$. Dissertação (Mestrado em Desenho Industrial) Faculdade de Arquitetura Artes e Comunicação, Universidade Estadual Paulista Bauru, 2003.

22 JONES, Sue Jenkyn Fashion design: manual do estilista. 2. ed. São Paulo: Cosac Naify, 2005.

23 BARCARO, Andrea. Os processos de uma empresa de moda. In: SORCINELLI, Paolo. (org.). Estudar a moda: corpos, vestuários, estratégias. São Paulo: Senac, 2008.

24 SORGER, Richard; UDA$L E$, Jenny. Fundamentos de design de moda. Porto Alegre: Bookman Companhia, 2009.

25 RENFREW, Elinor; RENFREW, Colin. Desenvolvendo uma coleção. Porto Alegre: Bookman, 2010.

26 TREPTOW, Doris. Inventando moda: planejamento de coleção. Brusque: Doris Treptow, 2013.

27 MONTEMEZZO, Maria C. F. S, op. cit., 2003.

28 lbidem.

29 JONES, Sue Jenkyn, op. cit., 2005. 
Barcaro $^{30}$ define como etapa inicial o portfólio das coleções, na qual são realizadas análises de marcas, investimentos e tendências. Na etapa seguinte, sistematização das coleções, considera importante a escolha do número de modelos para o mostruário, definição dos tecidos e cores, além do cronograma operacional. Segue, então, o desenvolvimento da coleção, iniciam-se os esboços e desenhos, a escolha de acessórios e a criação das peças piloto. Nesse momento projetual, é realizada a revisão das peças, distribuição e mostra da coleção. A finalização do projeto prevê a campanha, a produção e a compra e, por fim, a entrega da coleção.

Sorger e Udale ${ }^{31}$ iniciam a partir da pesquisa, sendo elas a de tendências e a de mercado. Posteriormente, inicia-se a geração de alternativas, por meio dos esboços, depois a modelagem e a pilotagem. Por fim, a confecção e a finalização da coleção.

Renfrew e Renfrew ${ }^{32}$ escrevem que uma coleção de moda exige muita pesquisa, investigação e planejamento. Inicia-se o processo pelo briefing, em seguida vem a modelagem, o protótipo. Destacam os processos comerciais que envolvem uma coleção de moda, como se observa na Figura 1.

Treptow $^{33}$ descreve as quatro etapas detalhadamente. Inicia o projeto com a etapa do planejamento, que confere a reunião de planejamento, o cronograma, o parâmetro e a dimensão da coleção. Também faz parte da etapa do planejamento o briefing e a pesquisa de tendências. A segunda etapa é a do design, a qual é composta por inspiração, seleção de cores, tecidos, aviamentos. Além disso, a autora introduz nessa etapa os elementos e princípios do design, os elementos de estilo, que auxiliam na criação dos esboços, dos desenhos de moda, desenho técnico. A terceira etapa é a do desenvolvimento, referente à modelagem, à confecção do protótipo, aprovação, graduação, encaixe, a realização da ficha técnica, além da formação de preço, a confecção do mostruário e a produção. Na quarta e última etapa, Treptow ${ }^{34}$ dá ênfase para a promoção e comercialização. Aqui são considerados o lançamento, a divulgação, a comercialização, as entregas e a reunião de feedback. Na Figura 1 constam, respectivamente, as metodologias projectuais desses autores para planejar os produtos de moda. 


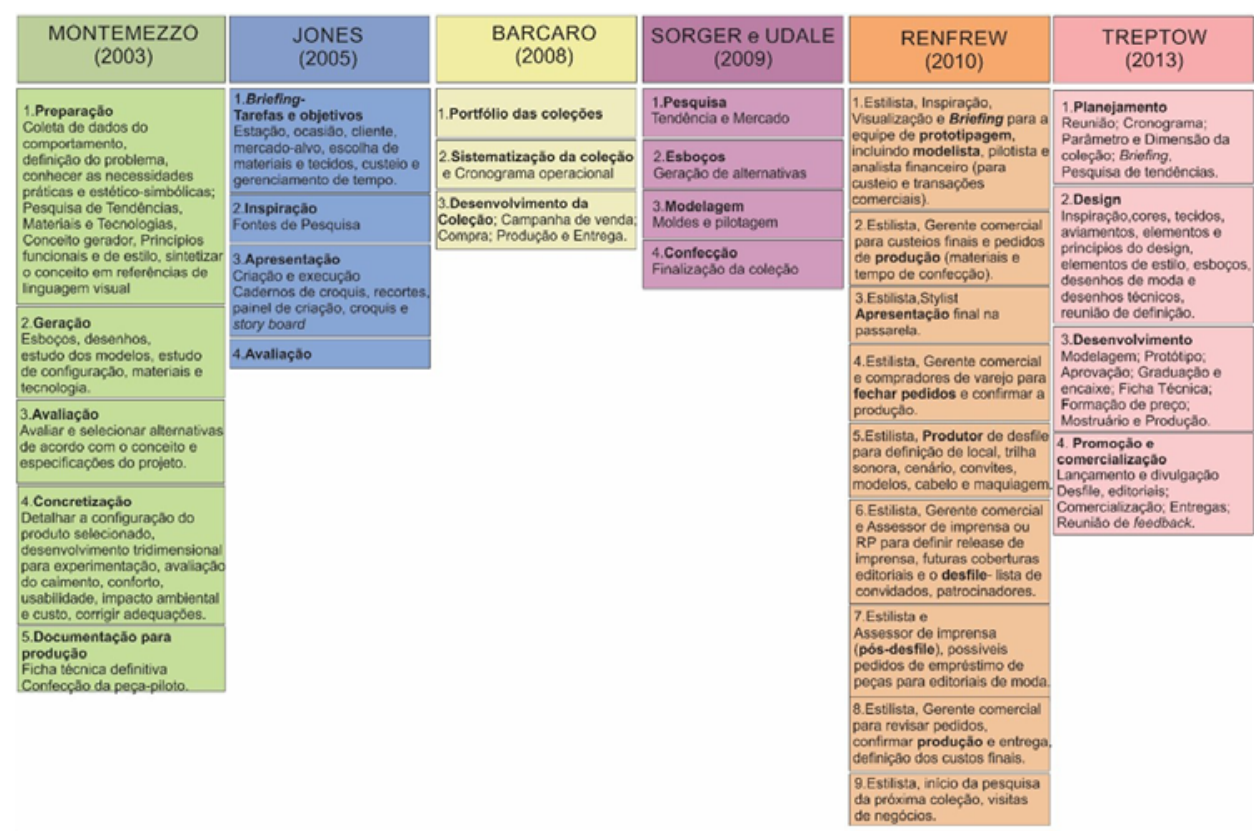

Figura 1: Metodologias projetuais para desenvolvimento de coleção de moda

Apesar de haver metodologias projetuais para o desenvolvimento de coleções de moda, nota-se que, muitas vezes, no processo de planejamento de um projeto, as etapas acontecem em ordem inversa, e há casos em que se opta por eliminar etapas que são determinantes para se obter êxito na coleção. Afinal, são etapas intermediárias para a aplicação de diversos saberes que dão consistência ao projeto. Por consequência, é relevante a busca por metodologias, ferramentas que possam auxiliar projetos na área de moda, para acompanhar suas manifestações cíclicas.

\section{EDUCOMUNICAÇÃO NO ENSINO E NO DESENVOLVIMENTO DE COLEÇÕES DE MODA}

Morin $^{35}$ coloca que o formato educacional atual está em crise por conta da departamentalização cartesiana do conhecimento, que criou inúmeras especialidades. Entretanto, acabou esquecendo a conexão existente entre elas e, além disso, ignorou a conexão com a realidade e com o próprio ser humano. Com base nessas considerações, o autor defende a necessidade de se fazer a transição entre o pensamento cartesiano linear para o pensamento sistêmico e complexo, com o objetivo de promover a formação de cidadãos com mentes abertas para o novo e para a diversidade, conhecer o contexto que os cerca e comprometidos com o desenvolvimento individual e social.

Carvalhal $^{36}$ cita Paul Baran (1926-2011), que, durante a Guerra Fria, percebe que as estruturas da sociedade estavam mudando e era necessário adotar

35 MORIN, Edgar, op. cit., 2000. cit., 2016 
novas conexões para mudar o todo. Duran foi responsável pela criação da rede de comutação em pacotes (Figura 2).

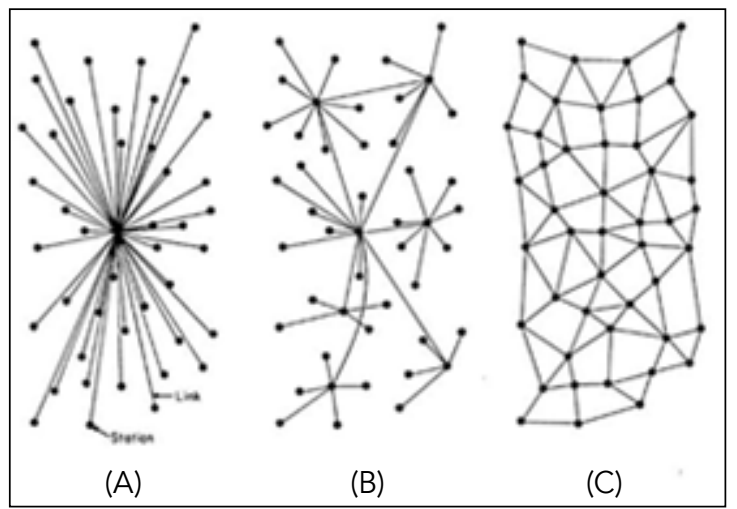

Figura 2: Diagrama de Paul Baran

O desenho (A) traduz o momento em que tudo era centralizado e distribuído de "um para muitos" (criação, informação, poder, dinheiro). A sociedade moderna descentralizou e o modelo foi fragmentado (B). Assim, surgiram os departamentos, os grupos, as escolas, as novas religiões. Por fim, o terceiro desenho $(\mathrm{C})$ representa a atualidade, todos conectados a uma grande rede, possibilitando muito mais acesso à informação e ao poder, cada um é parte do todo. A ampliação da consciência é favorecida por esse modelo ${ }^{38}$.

Carvalhal $^{39}$ escreve que a forma de planejamento ou o modelo cartesiano não darão conta de explicar ou prever "a nova era da moda". Diante dessa constatação, o autor pondera que, para entender a moda daqui para frente, é necessário que se olhe primeiramente para as pessoas.

O ensino é um processo complexo que utiliza a mediação de algum tipo de meio de comunicação como complemento à ação do professor em sala de aula, a fim de auxiliar sua interação com os alunos. Nessa mesma direção, a educomunicação como interface entre educação e comunicação tem a finalidade de estimular a aprendizagem, aproveitar os saberes de cada indivíduo em uma

37 Ibibem, p. 129

38 CARVALHAL, André, op. cit., 2016.

39 lbidem, p. 56.

40SOARES, Ismar de Oliveira. Alfabetização e Educomunicação: o papel dos meios de comunicação e informação na educação de jovens e adultos ao longo da vida. São Paulo: USP, 2003. Disponível em: http:// www.usp.br/nce/wcp/arq/ textos/89. pdf. Acesso em: 10 mar. 2016. p. 1. construção coletiva do conhecimento. Para Soares ${ }^{40}$, educomunicação é

o conjunto das ações inerentes ao planejamento, implementação e avaliação de processos e produtos destinados a criar e fortalecer ecossistemas comunicativos em espaços educativos, melhorar o coeficiente comunicativo das ações educativas, desenvolver o espírito crítico dos usuários dos meios massivas, usar adequadamente os recursos da informação nas práticas educativas, e ampliar capacidade de expressão das pessoas.

É relevante salientar que os projetos educomunicativos indicam para uma educação pedagógica, pela interdisciplinaridade, valorizando as habilidades e competências. Agregar a educomunicação às estratégias utilizadas no âmbito 
escolar torna este um ambiente dinâmico favorável a uma aprendizagem colaborativa e conjunta.

Sob essa perspectiva, percebe-se que a educomunicação pode contribuir para a criação de uma coleção de moda, pois a moda tem características de valorização de um repertório cultural, em que o significado é construído pela integração da percepção humana. Com o tempo, o espaço, a cultura e a memória $^{41}$ também passam a fazer parte do conceito de educomunicação.

Nesse viés, convém enfatizar que a educomunicação pressupõe o compartilhamento das informações, considerando que o conhecimento é de e para todos. A educomunicação é um novo campo que nasce da junção da comunicação e da educação, alguns argumentam como uma metodologia que pensa e pratica a comunicação de forma colaborativa ${ }^{42}$. Para Carvalhal ${ }^{43}$, "colaborar é uma resposta das pessoas às transformações que estamos vivendo". Carvalhal enfatiza, ainda, que a moda é veículo de comunicação a serviço da sociedade, e deve ser um agente de transformação e de veiculação de ideias.

É relevante salientar que a educomunicação, enquanto "teia de relações (ecossistema) inclusivas, democráticas, midiáticas e criativas - não emerge espontaneamente num dado ambiente. Precisa ser construída intencionalmente" ${ }^{44}$. A moda, por sua vez, também precisa ser construída intencionalmente, ser mais consciente, mais humana, colaborativa, sustentável, social e ética ${ }^{45}$.

Sanches ${ }^{46}$ salienta a importância do contexto para o ensino e a aprendizagem, além das atividades interativas e flexíveis do ambiente educacional, que são fundamentais no processo investigativo em sala de aula. Sob esse direcionamento, a autora aponta a importância do processo colaborativo na construção do conhecimento. A autora vai além e esclarece a conexão vestuário-contexto. $\mathrm{O}$ vestuário tem a função de proteger e também estabelecer a aparência para a integração no contexto sociocultural. De forma paralela, a educomunicação leva em consideração o contexto social e, a partir de uma pesquisa sobre para quem a comunicação está direcionada, decide-se o tipo de linguagem e de mídia mais adequadas para a geração dos produtos.

Um processo projetual surge da demanda do contexto sociocultural e finaliza no mesmo contexto que o definiu, transformando e influenciando novas demandas. O reconhecimento dessa premissa, conforme Sanches ${ }^{47}$, é primordial ao processo de ensino/aprendizagem de projetos. Os movimentos socioculturais são imprescindíveis para projetar uma coleção de moda, pois geram padrões de comportamento, "introduzindo e renovando códigos comunicativos na dinâmica social vigente, a qual está em sintonia direta com as significações construídas pela moda” ${ }^{\text {. }}$.

\section{METODOLOGIA}

A metodologia do trabalho se baseia em pesquisa exploratória de caráter bibliográfico. No texto, expõe-se uma breve compreensão sobre metodologias projetuais no ensino e no desenvolvimento de coleções de moda a partir de
41 SANCHES, Maria Celeste de Fátima, op. cit., 2017.

42 Disponível em: file:///C:/ Users/14047/Downloads/ guia_de_educomunicacao_-viracao_2011-george.pdf. Acesso em: 12 mar. 2016. p. 21.

43 CARVALHAL, André, op. cit., 2016. p. 147.

44 SOARES, Ismar de Oliveira. Educomunicação: 0 conceito, o profissional, a aplicação. São Paulo: Paulinas. 2011. p. 37.

45 CARVALHAL, André, op. cit., 2016.

46 SANCHES, Maria Celeste de Fátima, op. cit., 2017. 47 Ibidem.

48 lbidem, p. 67. 
49 CARVALHAL, André, op. cit., 2016. p. 66.

50 Seguindo a mesma linha de raciocínio, o consultor em liderança, Simon Sinek (apud CARVALHAL, 2016) criou o Golden Circle, pois acredita que as pessoas não compram o que você faz, mas sim, pelo motivo de fazer o que você faz.

51 Calligra Flowé um aplicativo de diagramação e fluxograma fácil de usar, com forte integração com os outros aplicativos da Calligra. Permite criar diagramas de rede, organogramas, fluxogramas (https://calligra.org/ old-components/).

52 Mood boards são painéis em que as informações são expressas utilizando os mais variados recursos, como amostras de materiais, esboços, fotografias, recortes, textos, ilustrações, fotocópias etc. (RENFREW: RENFREW, 2010; SORGER; UDALE, 2009).

53 GIMP - GNU Image Manipulation Program - programa para edição de imagens (https://www.gimp. org/).

54 Voki - é uma ferramenta que, integrada com outras num contexto de trabalho colectivo, pode tornar-se um instrumento motivador para a comunicação e para o desenvolvimento do discurso oral e estruturação do pensamento (http://ferramentaseducativas.com/ index.php/multimedia/video/72-voki-o-avatarque-fala).

55 Podcast-é um conteúdo em áudio, disponibilizado através de um arquivo ou streaming, que conta com a vantagem de ser escutado sob demanda, quando o usuário desejar. Pode ser ouvido em diversos dispositivos. https://resultadosdigitais.com.br/blog/ como-criar-um-podcast/).
Montemezzo (2003), Jones (2005), Barcaro (2008), Sorger e Udale (2009), Renfrew e Renfrew (2010) e Treptow (2013) entre outros. E, na sequência, apresenta-se a proposta prática de "Metodologia projectual para educomunicar o desenvolvimento de coleções de moda”.

\section{APRESENTAÇÃO DA PROPOSTA PRÁTICA}

O planejamento das práticas educomunicativas foi elaborado juntamente com uma metodologia projetual. Para tal, as práticas foram distribuídas em um semestre letivo, de acordo com o calendário acadêmico e o planejamento pedagógico de um curso de Design de Moda.

A proposta era fazer uma coleção, de forma colaborativa, treinando a habilidade de solucionar problemas coletivamente, que é considerada uma característica tanto da educomunicação como do design. Por meio da cocriação, será desenvolvida apenas uma coleção da turma, na qual todos os alunos participarão do projeto. Carvalhal ${ }^{49}$ (2016) defende que a cocriação é como uma evolução da colaboração.

A metodologia para a coleção proposta neste trabalho foi desenvolvida em três etapas. A primeira etapa, nomeada como Planejamento, contempla objetivo, problematização e Golden Circle $e^{50}$ : Por quê? Como? O quê?; Além de cronograma, dimensão e parâmetro. Já a segunda etapa é composta pelas pesquisas de comportamento, mercado, tendências e sustentabilidade. Por fim, a terceira etapa é denominada Book de coleção e é subdividida em: Conceito, Release, Lifestyle, Parâmetros de Moda, Materiais e aviamentos, Design de superfície, Cores e Mapa da coleção.

Primeiramente, destaca-se que a intenção, o propósito da coleção, que Carvalhal classifica como "a declaração da diferença que você pretende fazer no mundo”. Nesse item, será trabalhado com o Golden Circle. Para isso, a prática educomunicativa escolhida é a entrevista. Para a realização dessa prática, será organizado um roteiro de perguntas sobre o planejamento da coleção. As entrevistas serão elaboradas pela metade da turma e a outra metade serão os entrevistados.

Ainda na etapa do planejamento, no que se refere ao Cronograma, a dimensão e o parâmetro, a prática educomunicativa é a realização de diagramas, com a ferramenta Calligra Flow ${ }^{51}$, de forma que organize e facilite a visualização. No que se refere às pesquisas, serão elaborados painéis, mood-board ${ }^{52}$, a fim de aprimorar a capacidade de síntese e expressão por meio de imagem. Nessa etapa será utilizada a ferramenta Gimp ${ }^{53}$, que pode ser utilizada para a edição de imagens. Para a pesquisa sobre sustentabilidade, será utilizada a ferramenta Voki54 para listar.

A etapa de construção do "Book de coleção" será executada nas versões digital e impressa. As etapas seguintes compõem o book. Para o release da coleção, será feito um podcast $t^{5}$. O painel lifestyle será composto por fotos. Os parâmetros de moda serão apresentados por meio de editoriais e montagens. Tanto a cartela de materiais e aviamentos como a etapa do design têxtil serão apresentadas com cartaz. A cartela de cores e combinações será um jogo. Para finalizar a prática educomunicativa, será gravado um vídeo contemplando todas as etapas da coleção. 
Na Figura 3, destaca-se a prática educomunicativa em cada etapa do processo projetual.

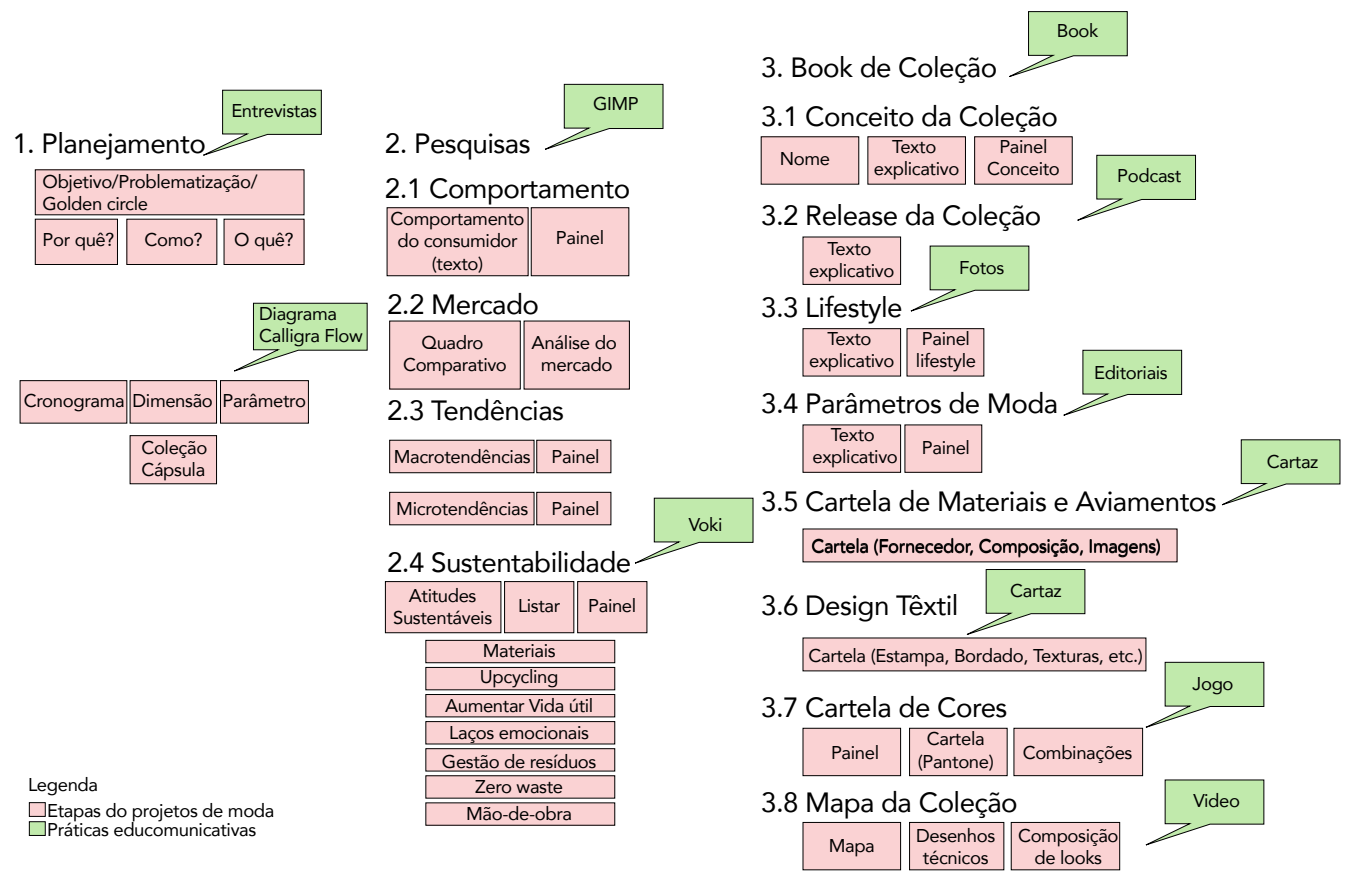

Figura 3: Metodologia projetual e práticas educomunicativas

Fonte: Elaboração própria

Para o projeto da disciplina, serão utilizadas várias práticas educomunicativas, que contribuem para o ensino de cada etapa, de maneira que o protagonismo do estudante se sobressaia e que cada etapa seja entendida isoladamente, mas também como se interligam e se conectam com o contexto em questão.

Cabe ressaltar que o processo projetual e as práticas educomunicativas serão realizados durante todo o semestre, com a proposta de desenvolver apenas uma coleção de moda, que acontecerá de forma colaborativa com o propósito de pensar na sustentabilidade e respeito ao ser humano.

\section{CONSIDERAÇÕES FINAIS}

No processo colaborativo de criação, busca-se a horizontalidade nas relações entre os envolvidos. Isso significa que se procura prescindir de qualquer hierarquia pré-estabelecida e, portanto, são eliminados espaços exclusivos no processo de criação. Todos colaboram, conjuntamente, em todas as etapas do processo. A metodologia projectual para desenvolver uma coleção de moda de forma colaborativa possibilita treinar a habilidade de solucionar problemas coletivamente, característica da educomunicação e do design. 
Do ponto de vista operacional, é notório que o processo projetual surge da demanda do contexto e finaliza no contexto. Portanto, cada projeto deve ter uma metodologia flexível e de integração, considerando a complexidade do cenário.

Em síntese, infere-se que as metodologias projectuais para o desenvolvimento de coleções de moda podem utilizar-se de práticas educomunicativas para potencializar e assim tornar mais fácil o processo de ensino no desenvolvimento de coleções, articulando o processo colaborativo entre os alunos.

Com a educomunicação, prima-se por uma educação, por uma comunicação, por uma moda que pensa o ser humano como um todo e que respeita a identidade, $o$ significado e o propósito de vida por meio de conexões entre o individual e o social.

\section{REFERÊNCIAS BIBLIOGRÁFICAS}

ALVES, Gláucia da Rosa do Amaral; BECKER, Elsbeth Léia Spode. Manuais de etiqueta e civilidade e sua influência na condução social feminina no Brasil (1940-1960) . Revista Latino-americana de Geografia e Gênero, Ponta Grossa, v. 10, n. 2, p. 42-65, 2019.

APARICCI, Roberto. Educomunicação: mais além dos 2.0. São Paulo: Paulinas, 2014.

BARCARO, Andrea. Os processos de uma empresa de moda. In: SORCINELLI, Paolo (org.). Estudar a moda: corpos, vestuários, estratégias. São Paulo: Senac, 2008. p. 143-156.

BAUMAN, Zygmunt. Modernidade líquida. Rio de Janeiro: Zahar, 2001.

BRAUNSTEIN, Philippe. A emergência do indivíduo: abordagens da intimidade nos séculos XIV-XV. In: DUBY, Georges (org.). História da vida privada 2: da Europa feudal à Renascença. São Paulo: Companhia das Letras, 1990. p. 528

CARVALHAL, André. Moda com propósito. São Paulo: Paralela, 2016.

CIETTA, Enrico. A economia da moda: porque hoje um bom modelo de negócios vale mais do que uma boa coleção. São Paulo: Estação das Letras e Cores, 2017.

FLANDRIN, Jean-Louis. A distinção pelo gosto. In: CHARTIER, Roger (org.). História da vida Privada 3: da Renascença ao século das Luzes. São Paulo: Companhia das Letras, 2009. p. 234-289.

HALL, Stuart. A identidade cultural na pós-modernidade. Tradução de Tomas Tadeu da Silva e Guaracira Lopes Louro. 11. ed. Rio de Janeiro: DP\&A, 2006. HUNT, Alan. Governance of the consuming passions: a history of sumptuary law. New York: St. Martin`s Press, 1996. 
JONES, Sue Jenkyn. Fashion design: manual do estilista. 2. ed. São Paulo: Cosac Naify, 2005.

MONTEMEZZO, Maria C. F. S. Diretrizes metodológicas para o projeto de produtos de moda no âmbito acadêmico. 2003. Dissertação (Mestrado em Desenho Industrial) - Faculdade de Arquitetura, Artes e Comunicação, Universidade Estadual Paulista, Bauru, 2003.

MORAES, Dijon de. Metaprojeto: o design do design. São Paulo: Blucher, 2010.

MORIN, Edgar. Os sete saberes necessários à educação do futuro. São Paulo: Cortez, 2000.

RENFREW, Elinor; RENFREW, Colin. Desenvolvendo uma coleção. Porto Alegre: Bookman, 2010.

SANCHES, Maria Celeste de Fátima. Moda e projeto: estratégias metodológicas em Design. São Paulo: Estação das Letras, 2017.

SHULMAN, Rachel. Sumptuary legislation and the fabric construction of national identity in early modern England. Constructing the Past, Chicago, v. 8, n. 1, 2007.

SOARES, Ismar de Oliveira. Educomunicação: o conceito, o profissional, a aplicação. São Paulo: Paulinas, 2011.

SOARES, Ismar. Comunicação/educação, a emergência de um novo campo e o perfil de seus profissionais. Revista Contato, Brasília, DF, v. 1, n. 1, p. 19-74, 1999.

SOARES, Ismar de Oliveira. Alfabetização e educomunicação: o papel dos meios de comunicação e informação na educação de jovens e adultos ao longo da vida. São Paulo: USP, 2003. Disponível em: http://www.usp.br/nce/wcp/ arq/textos/89. pdf. Acesso em: 10 mar. 2016.

SORGER, Richard; UDALE, Jenny. Fundamentos de design de moda. Porto Alegre: Bookman Companhia, 2009.

SVENDSEN, Lars. Moda: uma filosofia. Rio de Janeiro: Zahar, 2010.

TREPTOW, Doris. Inventando moda: planejamento de coleção. Brusque: Doris Treptow, 2013. 